\title{
Ag nanoparticles induced modification in microhardness of polyvinyl alcohol
}

\author{
Isha Saini ${ }^{1}$, Annu Sharma ${ }^{1 *}$, Naveneet Chandak ${ }^{2}$, Sanjeev Aggarwal ${ }^{1}$, Pawan K. Sharma ${ }^{2}$ \\ ${ }^{1}$ Department of Physics, Kurukshetra University, Kurukshetra 136119, India \\ ${ }^{2}$ Department of Chemistry, Kurukshetra University, Kurukshetra 136119, India
}

*Corresponding author

DOI: $10.5185 / \mathrm{amp} .2018 / 6777$

www.vbripress.com/amp

\begin{abstract}
Silver (Ag) nanoparticles play a significant role in nanomaterials science and technology due to many peculiarities. One of the main characteristic of Ag nanoparticles is the occurrence of surface plasmon resonance (SPR) due to the collective oscillation of free electrons in visible region. Due to this distinctive feature Ag nanoparticles have numerous applications such as in catalysis, surface enhanced Raman spectroscopy, photonics, solar cells etc. In the present work, no additional stabilizing agent has been used. The characteristic SPR peak appears at around $405 \mathrm{~nm}$ in UV-Visible absorption spectra of PVA-Ag nanocomposite films, thereby confirming the nanocomposite formation. The synthesized nanocomposite films were structurally characterized using fourier transform infrared (FTIR) and Raman spectroscopy. FTIR spectra of PVA-Ag nanocomposite film indicates that PVA matrix is modified by Ag nanoparticles which is in agreement with the results obtained using Raman spectroscopy. TEM as well as FE-SEM micrographs reveal that Ag nanoparticles are mostly spherical in shape. The knoop microhardness number of the nanocomposites was found to increase from 2.4 $\mathrm{Kgf} / \mathrm{mm}^{2}$ for PVA to $12.1 \mathrm{kgf} / \mathrm{mm}^{2}$ for PVA-Ag nanocomposite film loaded with $0.062 \mathrm{wt} \% \mathrm{Ag}$ nanoparticles. Copyright @ 2018 VBRI Press.
\end{abstract}

Keywords: Ag nanoparticles, nanocomposites, structure, microhardness, SPR.

\section{Introduction}

Polymer nanocomposite technology is one of the driving forces in stimulating and promoting nanotechnological developments. Intense research in the field of synthesis and study of composite materials containing metal nanoparticles is motivated by the remarkable properties exhibited by such composites leading to their various potential applications in diverse disciplines of science and technology. Nanocomposites fabricated using metallic nanoparticles, such as $\mathrm{Ag}, \mathrm{Au}$, $\mathrm{Cu}$ has been an area of intensive research [1-4]. One of the main characteristic of these nanoparticles is the occurrence of surface plasmon resonance (SPR) in the visible region which is due to the resonance of free electrons oscillation with the illuminating light. Ag nanoparticles have drawn considerable interest of researchers around the world as the nanofillers for reinforcing polymeric matrices because it shows a sharp and distinct SPR and has $10^{5}-10^{6}$ times larger extinction cross section [5-7]. The SPR can be tuned to any wavelength in the visible spectrum by changing the shape, size or concentration of nanoparticles [5]. Higher efficiency of $\mathrm{Ag}$ nanoparticles to plasmon excitation leads to enhanced properties including catalysis, electrical conductivity, antimicrobial activity, surface enhanced raman scattering etc [8-10]. These extraordinary features make them a potential candidate for numerous applications such as biosensors [11], photonics [12], colour filter technology [13], photovoltaic applications [14] etc.

PVA is an excellent host for the nanofillers as it is a hydrophilic, nontoxic and biodegradable polymer and thus has numerous technological applications. Because of the establishment of strong hydrogen bonding between the functional group of PVA and the water molecules, it has excellent water solubility. However, the main drawback of this hydrophilic polymer is its poor mechanical strength. For the improvement in these performance properties and in order to increase applications of PVA in various fields, researchers are using emergent field of nanotechnology by incorporating nanoparticles into PVA matrix to produce novel materials. There are quite a few reports in literature which have highlighted the improvement of hardness of PVA by incorporating various nanoparticles. Enhancement in microhardness of PVA with increasing concentration of chromium chloride has been observed by Khaled [15]. Bakr et al. have shown improvement in microhardness of PVA with the incorporation of increasing concentration of $\mathrm{PbCl}_{2}[\mathbf{1 6}]$.

However, in literature to the best of our knowledge there are no reports available on the enhancement of microhardness of PVA by incorporation of $\mathrm{Ag}$ nanoparticles. A systematic study needs to be done on the evaluation of mechanical properties of Ag-PVA 
nanocomposite, so that it can be utilized for high strength applications. These properties keep on evolving depending on size, type, concentration and interaction of nanoparticles with the host matrix. Extent of homogeneous distribution as well as the polymernanoparticle interaction determines the hardness of the nanocomposite.

Hence, in the present work a systematic and detailed investigation has been carried out to understand the variation in structural and mechanical properties of PVA with increasing concentration of $\mathrm{Ag}$ nanoparticles. PVA-Ag nanocomposites were first structurally characterized using FTIR and raman spectroscopy subsequently variation in the microhardness as a function of increased concentration of Ag nanoparticles in PVA was studied.

\section{Experimental}

\section{Materials details}

All chemicals used were of analytical reagent grade and were used as received. Silver nitrate $\left(\mathrm{AgNO}_{3}\right)$ was purchased from Rankem (molecular weight $=169.87$ $\mathrm{g} / \mathrm{mol}$ ) while polyvinyl alcohol (PVA) (molecular weight $=1,25,000 \mathrm{~g} / \mathrm{mol}$ ) and sodium borohydride $\left(\mathrm{NaBH}_{4}\right)$ were purchased from Ranbaxy. Double distilled water was used to prepare all the solutions.

\section{Formation of Silver (Ag) nanoparticles}

$\mathrm{AgNO}_{3}$ was reduced using $\mathrm{NaBH}_{4}$ to prepare $\mathrm{Ag}$ nanoparticles. $0.017 \mathrm{~g}$ of $\mathrm{AgNO}_{3}$ dissolved in $10 \mathrm{ml}$ distilled water was added drop by drop to an ice-bath cooled solution of $0.02 \mathrm{~g}$ of $\mathrm{NaBH}_{4}$ dissolved in $300 \mathrm{ml}$ of water under continuous magnetic stirring. After whole of the nitrate solution was mixed, a clear yellow solution was obtained. Hence, the above process results in the formation of $\mathrm{Ag}$ nanoparticles.

\section{Fabrication of PVA-Ag nanocomposites}

For the fabrication of PVA-Ag nanocomposite, the Ag solution (described above) was mixed in varying concentrations with the solution of PVA with the help of a magnetic stirrer. The resulting composite solutions were then poured in glass petri-dishes and allowed to rest for the evaporation of solvent in the absence of light. After about 3-4 days, yellow transparent PVA-Ag nanocomposite films were peeled off. Pure PVA films were prepared in the same manner for comparison. The samples were kept away from light.

\section{Characterization}

Molecular interactions between functional groups of PVA and Ag nanoparticles and the changes induced in PVA after integration of Ag nanoparticles were studied using Perkin Elmer FTIR spectrometer in the range of $4000-400 \mathrm{~cm}^{-1}$ and a Dilor raman spectrometer using $532 \mathrm{~nm}$ wavelength laser.

Quanta 200F field effect scanning electron microscope was used to study the morphology of nanocomposite films. A very thin layer of gold was sputtered on the surface of nanocomposite films and the coated films were subjected to FE-SEM studies.

UHL microhardness tester using a Knoop indenter was utilized for surface hardness measurements. For these measurements load of $9.8 \mathrm{mN}$ was applied for indentation time of $30 \mathrm{~s}$.

\section{Results and discussion}

\section{Structural characterization}

Fig. 1 presents the FTIR spectra of PVA and PVA-Ag nanocomposite film containing $0.062 \quad \mathrm{wt} \% \quad \mathrm{Ag}$ nanoparticles. Fig. 1 curve (a) display stretching vibrations of $\mathrm{O}-\mathrm{H}$ and $\mathrm{C}-\mathrm{H}$ bonds at around $3332 \mathrm{~cm}^{-1}$ and $2938 \mathrm{~cm}^{-1}$ respectively. The stretching vibrations of $\mathrm{C}=\mathrm{O}$ and $\mathrm{C}-\mathrm{O}$ bonds at $1730 \mathrm{~cm}^{-1}$ and $1255 \mathrm{~cm}^{-1}$ are attributed to the residual acetyl group present in PVA. The vibrational peaks at $1434 \mathrm{~cm}^{-1}$ and $859 \mathrm{~cm}^{-1}$ are assigned to $\mathrm{C}-\mathrm{H}$ bending and stretching mode of PVA respectively. Peak at $1097 \mathrm{~cm}^{-1}$ is assigned to $\mathrm{C}-$ $\mathrm{O}$ stretching vibrations in PVA. Hence, the monomer structure of PVA has been confirmed. The assignment of various peaks made in this study agrees well with the peaks reported in literature $[\mathbf{1 7}, \mathbf{1 8}]$. It can be clearly seen from figure 1 (curve b) that after the addition of Ag nanoparticle in PVA matrix most of the peaks are diminished in intensity and are slightly displaced towards higher wavenumber. The peak observed at $3332 \mathrm{~cm}^{-1}, 2938 \mathrm{~cm}^{-1}$ and at $1730 \mathrm{~cm}^{-1}$ has been shifted to $3341 \mathrm{~cm}^{-1}, 2948 \mathrm{~cm}^{-1}$ and $1739 \mathrm{~cm}^{-1}$ respectively in the FTIR spectra of PVA-Ag nanocomposite film. Peak at $1142 \mathrm{~cm}^{-1}$ due to the symmetric $\mathrm{C}-\mathrm{C}$ stretching mode, representing the crystalline regions in PVA disappear upon incorporation of $\mathrm{Ag}$ nanoparticles, indicating reduction in the crystalline phase of PVA [19].

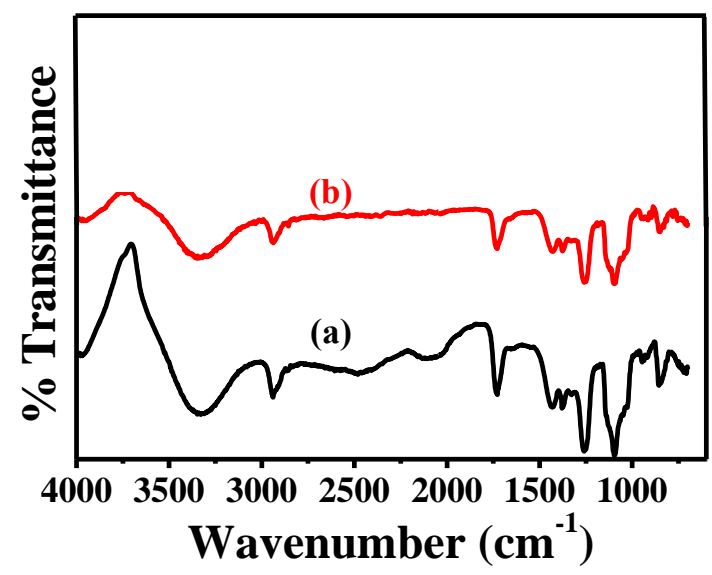

Fig. 1. FTIR spectra of (a) PVA and (b) PVA-Ag nanocomposite film with 0.062 wt $\% \mathrm{Ag}$ nanoparticles.

Another change in the FTIR spectra of PVA-Ag nanocomposite has been observed for the peaks at $1375 \mathrm{~cm}^{-1}$ and $1430 \mathrm{~cm}^{-1}$. In alcohols, the peak at $1375 \mathrm{~cm}^{-1}$ is the result of the coupling of the $\mathrm{O}-\mathrm{H}$ inplane vibrations at $1434 \mathrm{~cm}^{-1}$ with the $\mathrm{C}-\mathrm{H}$ wagging 
vibration $(\mathrm{CH}-\mathrm{OH})$. The decrease in the ratio between the intensities of this peak and the peak at $1434 \mathrm{~cm}^{-1}$ upon incorporation of $\mathrm{Ag}$ nanoparticles indicates the decoupling between $\mathrm{O}-\mathrm{H}$ and $\mathrm{C}-\mathrm{H}$ vibrations due to bonding interaction between $\mathrm{O}-\mathrm{H}$ group of PVA and $\mathrm{Ag}$ nanoparticles. Thus, it can be inferred that the addition of $\mathrm{Ag}$ nanoparticles leads to the structural rearrangement in PVA matrix [20].
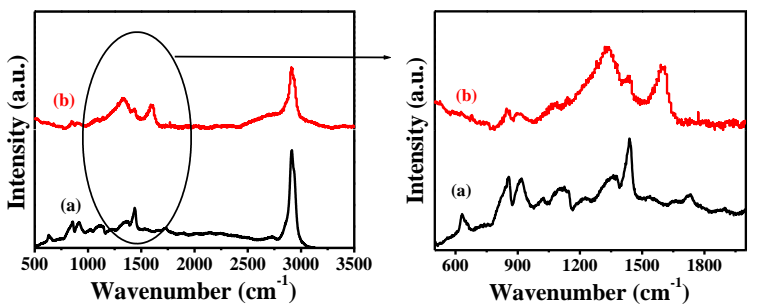

Fig. 2. Raman spectrum of (a) PVA and (b) PVA-Ag nanocomposite film with $0.062 \mathrm{wt} \%$ Ag nanoparticles.

Raman spectroscopy was further used to probe the molecular structure of synthesized nanocomposites. Fig. 2 presents the Raman spectra of PVA and PVA-Ag nanocomposite film with $0.062 \mathrm{wt} \% \mathrm{Ag}$ nanoparticles. In the Raman spectra of PVA, stretching vibrations of C-C bonds occurs at $854 \mathrm{~cm}^{-1}$ and $918 \mathrm{~cm}^{-1}$, peak at $1117 \mathrm{~cm}^{-1}$ belongs to the stretching vibrations of $\mathrm{C}-\mathrm{O}$ bond. The peak at $1362 \mathrm{~cm}^{-1}$ and $1462 \mathrm{~cm}^{-1}$ has been attributed to the bending vibrations of $\mathrm{C}-\mathrm{H}$ and $\mathrm{O}-\mathrm{H}$ bonds. The stretching vibrations at $2920 \mathrm{~cm}^{-1}$ are due to the of $\mathrm{C}-\mathrm{H}$ bond. The assignments of various peaks made in this study are in general agreement with the peaks reported in literature [21]. It can be clearly seen from figure 2 that peaks corresponding to various functional groups of PVA has been displaced and reduced in intensity after the addition of $\mathrm{Ag}$ nanoparticles in PVA matrix. Peaks at $854 \mathrm{~cm}^{-1}$ and $918 \mathrm{~cm}^{-1}$ due to C-C stretching vibrations have been shifted to $848 \mathrm{~cm}^{-1}$ and $910 \mathrm{~cm}^{-1}$ respectively. Moreover peaks at $1117 \mathrm{~cm}^{-1}$ due to $\mathrm{C}-\mathrm{O}$ stretching vibrations and at $2920 \mathrm{~cm}^{-1}$ due to $\mathrm{C}-\mathrm{H}$ stretching vibrations has been considerably reduced in intensity upon incorporation of $\mathrm{Ag}$ nanoparticles. The most significant difference in the Raman spectra of nanocomposite film can be observed in $1300-1600 \mathrm{~cm}^{-1}$ region (Fig. 2 enlarged view). Peaks observed in the Raman spectra of PVA-Ag nanocomposite film at 1331 and $1597 \mathrm{~cm}^{-1}$ corresponding to the disorder D band and graphite like $\mathrm{G}$ bands respectively [22] has been enhanced significantly which is attributed to the $\mathrm{Ag}$ nanoparticles induced surface enhanced raman scattering (SERS) effect [23]. It is well proven that the metallic nanomaterials act as effective SERS active substrates. According to the electromagnetic theory of SERS, enhancements depend on the excitation of the localized surface plasmon resonance, which is influenced by several significant parameters such as size, shape and nature of the nanoparticles [24]. PVA$\mathrm{Ag}$ nanocomposite films show the presence of characteristic surface plasmon resonance peak of $\mathrm{Ag}$ nanoparticles at around $405 \mathrm{~nm}$ as shown elsewhere
[25]. It was observed that the intensity of SPR peak increases with increasing concentration of $\mathrm{Ag}$ nanoparticles in PVA matrix and the peaks has been shifted to longer wavelengths with increasing concentrations [26]. This shift in the SPR peak may be ascribed to the increase in the particle size with increasing concentration or may be due to the wider particle size distribution within PVA. The band width, intensity and position of the SPR wavelength of these metal nanoparticles changes with particle size and shape and with the dielectric constant of the surrounding matrix [27].

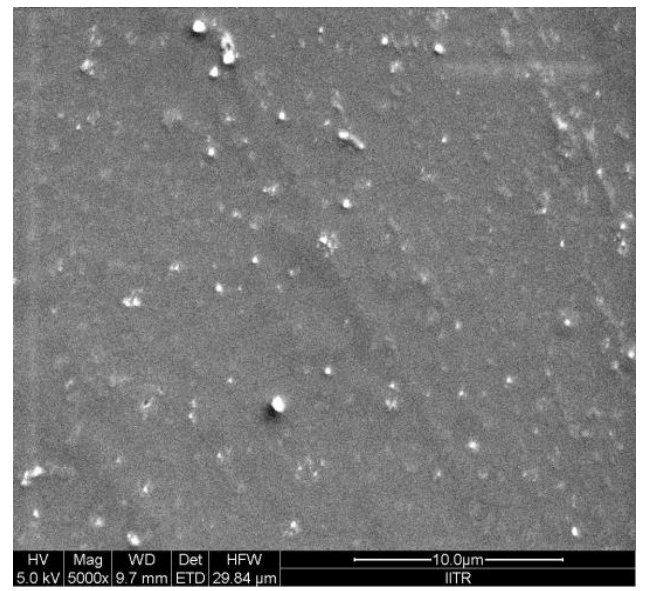

Fig. 3. FE-SEM micrograph of PVA-Ag nanocomposite film with $0.056 \mathrm{wt} \% \mathrm{Ag}$ nanoparticles.

Fig. 3 displays the FE-SEM micrograph of PVA$\mathrm{Ag}$ nanocomposite film containing $0.056 \mathrm{wt} \% \mathrm{Ag}$ nanoparticles. FE-SEM micrograph of PVA-Ag nanocomposite shows that $\mathrm{Ag}$ nanoparticles are homogenously distributed within the PVA matrix with a slightly deviated spherical symmetry which may be attributed to the interaction of $\mathrm{Ag}$ nanoparticles with PVA matrix. From the TEM micrograph (as depicted elsewhere [25]) the average size of Ag nanoparticles in PVA comes out to be $\sim 15 \pm 9 \mathrm{~nm}$. FE-SEM results are in excellent agreement with that obtained using TEM.

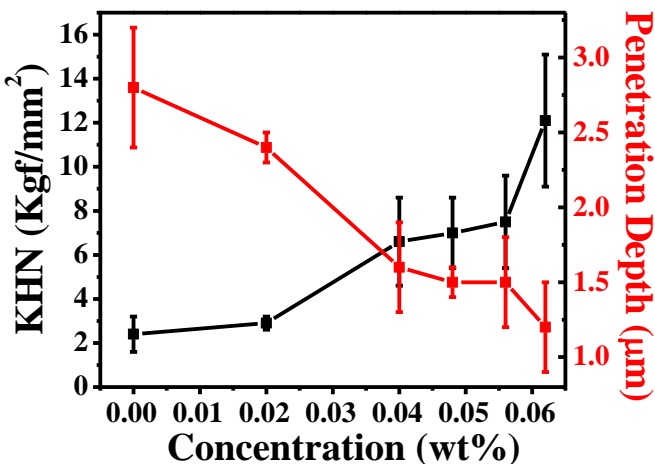

Fig. 4. Variation of hardness and penetration depth with respect to different concentration of $\mathrm{Ag}$ nanoparticles in PVA at $9.8 \mathrm{mN}$ load.

Fig. 4 presents the variation in Knoop microhardness and penetration depth for PVA as well as the nanocomposite films. Knoop indenter with a load of $9.8 \mathrm{mN}$ was utilized to produce indentations using a 
$30 \mathrm{sec}$ loading cycle. The microhardness $\left(\mathrm{H}_{\mathrm{k}}\right)$ values were obtained using [28]:

$H_{k}=14.23 \frac{p}{d^{2}} \times 10^{-6}$

where $\mathrm{H}_{\mathrm{k}}$ is expressed in $\mathrm{Kgf} / \mathrm{mm}^{2}$, the applied force $\mathrm{P}$ is in $\mathrm{mN}$ and the diagonal $\mathrm{d}$ is in $\mu \mathrm{m} .10$ imprints were made on the films and the average value was calculated.

The Knoop microhardness number (KHN) for PVA as well as PVA-Ag nanocomposite films was calculated using the equation (1). It can be discerned from Fig. 4 that the microhardness of PVA is $2.4 \mathrm{Kgf} / \mathrm{mm}^{2}$ and it increases to a value of $2.9 \mathrm{Kgf} / \mathrm{mm}^{2}$ for $0.02 \mathrm{wt} \% \mathrm{Ag}$ nanoparticles. With further increase in concentration of $\mathrm{Ag}$ nanoparticles to $0.062 \mathrm{wt} \%$ microhardness value reaches to $12.1 \mathrm{Kgf} / \mathrm{mm}^{2}$. Thus it can be inferred that the surface hardness of PVA is enhanced by the addition of $\mathrm{Ag}$ nanoparticles and it increases with increasing concentration of $\mathrm{Ag}$ nanoparticles in PVA matrix. From Fig. 4 it can also be seen that penetration depth decreases with increase in $\mathrm{Ag}$ nanoparticles concentration in PVA. Decreasing penetration depth with increasing concentration is also an indication of increased microhardness. This increase in microhardness value might be attributed to the increase in size of $\mathrm{Ag}$ nanoparticles in PVA matrix with the increasing concentration, as for a given volume, nanoparticles are much closer to each other and resists more strongly the penetration of indenter [29], thereby increasing the microhardness.

\section{Conclusion}

It can be concluded that PVA-Ag nanocomposites were prepared successfully without using any additional stabilizing agent. Resulting PVA-Ag nanocomposites were characterized structurally using FTIR and Raman spectroscopy which suggests the presence of molecular interaction between Ag nanoparticles and PVA matrix. FE-SEM image clearly reveal the uniform dispersion of spherical Ag nanoparticles within the PVA matrix. Emergence of characteristic surface Plasmon resonance peak of Ag nanoparticles at $405 \mathrm{~nm}$ in UV-Visible absorption spectra of PVA-Ag nanocomposites confirms the fabrication of nanocomposite. The knoop microhardness number of nanocomposites was found to increase with increasing concentration of $\mathrm{Ag}$ nanoparticles. It increases from $2.4 \mathrm{Kgf} / \mathrm{mm}^{2}$ for PVA to $12.1 \mathrm{kgf} / \mathrm{mm}^{2}$ for nanocomposite film with 0.062 wt\% Ag nanoparticles.

\section{Acknowledgements}

One of the authors (IS) acknowledges, UGC for providing basic scientific research fellowship to perform the research work.

\section{References}

1. Wu, K. H.; Yua, P. Y.; Hsieh, Y. J.; Yang, C. C.; Wang, G. P.; Polym. Degrad. Stab., 2009, 94, 2170.

DOI: $10.1016 /$ j.polymdegradstab.2009.09.007

2. Chaudhary, A.; Sens. Actuator. B-Chem, 2009, 138, 318. DOI: $10.1016 /$ j.snb.2009.01.019

3. Deka, H.; Karak, N.; Kalita, R. D.; Buragohain, A. K.; Polym. Degrad. Stab., 2010, 95, 1509.

DOI: $10.1016 /$ j.polymdegradstab.2010.06.017
4. Rozra, J.; Saini, I.; Aggarwal, S.; Sharma, A.; Adv. Mat. Lett., 2013, 4, 598.

DOI: $10.5185 /$ amlett.2013.1402

5. Kreibeg, U.; Vollmer, M.; Optical properties of metal clusters; Springer-Verlag: Berlin, 1995.

6. Lakowicz, J. R.; Anal. Biochem., 2005, 337,171.

DOI: $10.1016 /$ j.ab.2004.11.026

7. Barnes, W. L.; Dereux, A.; Ebbesen, T. W.; Nature, 2003, 424, 824.

DOI: 10.1038 /nature01937

8. Born, M.; Wolf, E.; Principles of optics; $7^{\text {th }}$ Ed. Cambridge University Press: UK, 1999.

9. Dastjerdi, R.; Montazer, M.; Colloid. Surface. B: Biointerfaces, 2010, 79, 5.

DOI: $10.1016 /$ j.colsurfb.2010.03.029

10. McFarland, A. D.; Van Duyne, R. P.; Nano Lett., 2003, 3 , 1057.

DOI: $10.1021 / \mathrm{n} 1034372 \mathrm{~s}$

11. Haes, A. J.; Zou, S.; Schatz, G. C.; Van Duyne, R. P.; J. Phys. Chem. B., 2004, 108, 109 .

DOI: $10.1021 / \mathrm{jp} 0361327$

12. Bockstaller, M. R.; Thomas, E. L.; J. Phys. Chem. B, 2003, 107 10017.

DOI: $10.1021 / \mathrm{jp} 035286 \mathrm{j}$

13. Quinten, M.; Appl. Phys. B, 2001, 73, 317. DOI: $10.1007 / \mathrm{s} 003400100666$

14. Adhyaksa, G. W. P.; Prima, E. C.; Lee, D. K.; Ock, I.; Yatman, S.; Yuliarto, B.; Kang, J. K.; Adv. Energy Mater., 2014, 4, DOI: $10.1002 /$ aenm. 201400470

15. Khaled, M. A.; Polym. Degrad. Stab., 1994, 43, 373. DOI: $0141-3910 / 94$

16. Bakr, N. A.; Hamid, M. I. A.; Hanafy, O. E.; J. Appl. Polym. Sci., 1995, 55, 415.

DOI: $0021-8995 / 95 / 0304$ 15-06

17. Andrade, G. I.,; Stancioli, E. F. B.; Mansur, A. A. P.; Vasconcelos, W. L.; Mansur, H. S.; J. Mater. Sci., 2008, 43, 450 .

DOI: $10.1007 / \mathrm{s} 10853-007-1953-7$

18. Mansur, H. S.; Sadahira, C. M.; Souza, A. N.; Mansur, A. A. P.; Mater. Sci. Eng. C, 2008, 28, 539.

DOI: $10.1016 /$ j.msec.2007.10.088

19. Ali, I. O.; Colloids and Surfaces A: Physicochem. Eng. Aspects, 2013, 436, 922 .

DOI: $10.1016 /$ j.colsurfa.2013.08.032

20. Mbhele, Z. H.; Salemane, M. G.; Van Sittert, C. G. C. E.; Nedeljkovic, J. M.; Djokovic, V.; Luytm, A. S.; Chem. Mater., 2003, 15, 5019.

DOI: $10.1021 / \mathrm{cm} 034505$ a

21. Tripathi, J.; Keller, J. M.; Das, K.; Tripathi, S.; Shripathi, T.; J. Phys. Chem. Solids, 2012, 73, 1026.

DOI: $10.1016 /$ j.jpcs.2012.03.011

22. Shekhawat, N.; Aggarwal, S.; Sharma, A.; Sharma, S. K.; Deshpande, S. K.; Nair, K. G. M.; J. Appl. Phys. 2011, 109, 083513.

DOI: $10.1063 / 1.3573480$

23. Lin, W. C.; Yang, M. C.; Macromol. Rapid Commun., 2005, 26,1942.

DOI: $10.1002 / \mathrm{marc} .200500597$

24. Tiwari, A. D.; Mishra, A. K.; Mishra, S. B.; Kuvarega, A. T.; Mamba, B. B.; Carbohyd. Polym., 2013, 92,1402.

DOI: $10.1016 /$ j.carbpol.2012.10.008

25. Saini, I.; Rozra, J.; Chandak, N.; Aggarwal, S.; Sharma, P. K.; Sharma, A.; Mater. Chem. Phys., 2013, 139, 802.

DOI: $10.1016 /$ j.matchemphys.2013.02.035

26. Khanna, P. K.; Singh, N.; Charan, S.; Subbarao, V. V. V. S.; Gokhale, R.; Mulik, U. P.; Mater. Chem. Phys., 2005, 93,117.

DOI: $10.1016 /$ j.matchemphys.2005.02.029

27. Kreibeg, U.; Vollmer, M.; Optical properties of metal clusters; Springer-Verlag: Berlin, 1995.

28. Dieter, G. E., Mechanical metallurgy; $3^{\text {rd }}$ Ed. McGraw Hill: USA, 1986

29. Dasari, A.; Rohrmann, J.; Misra, R. D. K.; Mater. Sci. Eng. A 2004, 364, 357

DOI: $10.1016 /$ j.msea.2003.08.058 